\title{
Değişik Yaş Gruplarındaki Güreşçilerde Bazı Antropometrik ve Motorik Performans Parametrelerinin Karşılaştırılması
}

\author{
Comparison of Some Anthropometric and Motoric Performance Parameters in Wrestlers of \\ Different Age Groups
}

Yener Aksoy ${ }^{*}$ - Hüseyin Aslan ${ }^{* *}$ - Osman İmamoğlu***

\begin{abstract}
In this study, it was aimed to compare some Anthropometric and motoric performance parameters of wrestlers in sportsman education centers. A total of 132 wrestlers were tested in athletes' training centers. One-way analysis of variance and Tukey tests were used for statistical analysis. The average age of athletes training wrestlers is 12 years old $(n=33) 11.94$ years and those in the 15 years category $(n=33) 14.88$ years. The length lengths were $147.24 \mathrm{~cm}$ and 12.4 years, and $159.45 \mathrm{~cm}$, respectively, while body weights were $41.24 \mathrm{~kg}$ and $56.48 \mathrm{~kg}$. There was a significant difference between age, body weight and height of wrestlers (p $<0.001$ ). There was a significant difference in age, bounce, long jump, hand grip strength, throwing medicine ball, 20 meter shuttle run, 30 meter speed run, number of shuttles taken in 30 seconds and sit and lie flexibility test values and anaerobic power values $(\mathrm{p}<0.001)$. The difference between the wrestlers' average 20 meters shuttle run, 30 meters speed run, and the number of sit-ups taken in 30 seconds and the flexibility to sit and sit according to age groups may also depend on age difference and the type of training they do. As a result, statistically significant differences were found in some anthropometric and motoric performance parameters of wrestlers in sports training centers according to age categories. It is thought that these differences arise from the difference of calendar and training ages of wrestlers as well as the type of training they do. It is advisable to give more weight to push and hand grip exercises as well as pulling exercises.
\end{abstract}

Structured Abstract: Purpose: In this study, it was aimed to compare some Anthropometric and motoric performance parameters of wrestlers in sportsman education centers.

\footnotetext{
* Çalışmada kullanılan veriler 2020 yılı öncesine aittir.

Dr. Öğr. Üyesi, Ondokuz Mayıs Üniversitesi, Yaşar Doğu Spor Bilimleri Fakültesi, Rekreasyon Bölümü, Asst. Prof. Dr., Ondokuz Mayls University, Yaşar Doğu Faculty of Sports Sciences, Recreation Departmen ORCID 0000-0002-1899-4096

El-mek: yener.aksoy@omu.edu.tr

** Öğr. Gör., Selçuk Üniversitesi, Spor Bilimleri Fakültesi, Beden Eğitimi ve Spor Bölümü

Lect,. Selcuk University, Faculty of Sports Sciences, Department of Physical Education and Sport

ORCID 0000-0001-7138-0643

El-mek: huseyinaslann6@gmail.com

**** Prof. Dr., Ondokuz Mayıs Üniversitesi Yaşar Doğu Spor Bilimleri Fakültesi, Spor Yöneticiliği Bölümü Prof. Dr., Ondokuz Mayıs University, Yaşar Doğu Faculty of Sports Sciences, Sports Management

ORCID 0000-0001-6671-6042

osmani55@ hotmail.com

Cite as/ Atıf: Aksoy, Y. \& Aslan, H. \& İmamoğlu, O. (2020). Değişik yaş gruplarındaki güreşçilerde bazı antropometrik ve motorik performans parametrelerinin karşılaştırılması. Turkish Studies, 15(3), 1473-1483. https://dx.doi.org/10.29228/TurkishStudies.41745

Received/Geliş: 12 February/Şubat 2020

Accepted/Kabul: 01 June/Haziran 2020

Copyright $(\mathrm{C}$ MDE, Turkey

Checked by plagiarism software Published/Yayın: 26 June/Haziran 2020 CC BY-NC 4.0
} 


\section{Method:}

Participants: A total of 132 wrestlers who regularly train at sports training centres in different provinces participated in the training. Participation occurred on a voluntary basis. The first measurement of the wrestlers was taken within the first week they came to wrestling training centres. The second measurement was taken a year later.

Training program of wrestlers in wrestling training center: Between May and June, plays and basic techniques in wrestling were taught. Between July and August, basic techniques, skills and condition moves were taught. Between October and November, basic techniques, tactics and endurance moves were taught. In December and January, basic techniques, tactics and endurance moves were continued. In February, March and April, matches for techniques, tactics and competitions were made. There were trainings for five days a week (A training of 550 hours a week). Loading intensity was kept between $50-60 \%$. Trainings included 20 minutes of gymnastic based warm-up, 40 minutes of basic-technique work out and 10 minutes of stretching.

Statistical analyses: SPSS 23.0 program was used to analyse the data. Normality was examined with Kolmogorov-Smirnov test. It was found that the data obtained were distributed normally. One-way analysis of variance and Tukey tests were used for statistical analysis. Significance level was taken as $\mathrm{p}<0.05$.

Results: The average age of the wrestlers in sports education centers is 11.94 years for those admitted at age 12 and 14.88 years for those in the 15-year category. The length lengths were $147.24 \mathrm{~cm}$ and 12.4 years, and $159.45 \mathrm{~cm}$, respectively, while body weights were $41.24 \mathrm{~kg}$ and $56.48 \mathrm{~kg}$. There was a significant difference between age, body weight and height of wrestlers ( $\mathrm{p}<0.001)$. In this study, the average squat jump values of wrestlers by age were found to be $22.97 \mathrm{~cm}$ for 12 years and $34.03 \mathrm{~cm}$ for 15 years. In this study, the average active jump values of the wrestlers by age were found to be $21.06 \mathrm{~cm}$ for the age of 12 and $32.21 \mathrm{~cm}$ for the age group of 15. In this study, anaerobic power value increased from $41.96 \mathrm{~kg} . \mathrm{m} / \mathrm{sec}$ for 12 age group to $70.72 \mathrm{~kg} . \mathrm{m} / \mathrm{sec}$ for 15 age group. In this study, the difference between jumping and long jump distances and anaerobic power values of wrestlers according to age groups may depend on the year and shape of their training, as well as age-related change. In this study, the hand grip strength of the wrestlers was $21.51 \mathrm{~kg}$ and the left hand was $21.56 \mathrm{~kg}$ for the age group of 12, while the right hand for the age group of 15 was $34.80 \mathrm{~kg}$ and the left hand was $34.82 \mathrm{~kg}$. In this study, the throwing of the wrestlers' health ball increased to $503.94 \mathrm{~cm}$ in the age group of 12 and $673.18 \mathrm{~cm}$ in the age group of 15 . In this study, the 30 meter speed run values decreased from an average of 5.30 seconds in the 12-year age group to 4.74 seconds in the 15-year age group. In this study, the number of shuttle wrestlers in 30 seconds was 21.57 in the age group of 12 , while 31.79 in the age group of 15. In this study, Sit-Nose Flexibility Test values decreased from an average of $33.94 \mathrm{~cm}$ in the age group of 12 to $27.86 \mathrm{~cm}$ in the age group of 15 . There was a significant difference in age, bounce, long jump, hand grip strength, throwing medicine ball, 20 meter shuttle run, 30 meter speed run, number of shuttles taken in 30 seconds and sit and lie flexibility test values and anaerobic power values $(p<0.001)$. The fact that the change in the 14-15 age group is insignificant in throwing a medicine ball can be attributed to the practice of training in wrestling, mostly in the pull type. In addition to pulling exercises, it can be suggested to give more weight to push and hand grip exercises. The difference between the wrestlers' average 20 meters shuttle run, 30 meters speed run, the number of sit-ups taken in 30 seconds and the flexibility to sit and sit according to age groups may also depend on age difference and the type of training they do. As a result, statistically significant differences were found in some anthropometric and motoric performance parameters of wrestlers in sports training centers according to age categories. It is thought that these differences arise from the difference of calendar and training ages of wrestlers as well as the type of training they do. It is advisable to give more weight to push and hand grip exercises as well as pulling exercises.

Keywords: Wrestler, Sportsman Education Center, Motor Performance

Öz: $\mathrm{Bu}$ çalışmada sporcu eğitim merkezlerinde bulunan güreşçilerin bazı Antropometrik ve motorik performans parametrelerinin karşılaştırılması amaçlanmıştır. Sporcu eğitim merkezlerinde toplam 132 güreşçi testlere tabi tutulmuştur. İstatistiksel işlemlerde tek yönlü varyans analizi ve Tukey testleri kullanılmıştır. Sporcu eğitim merkezleri güreşçilerinin yaş ortalaması 12 yaşında olanlar ( $n=33) 11,94$ yıl ve 15 yaş kategorisinde olanlar ( $\mathrm{n}=33)$ 14,88 yıl şeklindedir. Boy uzunlukları ise 12 yaşında kabul edilenler 147,24 cm ve 15 yaşında kabul edilenler 159,45 cm iken vücut ağırlıkları ise 41,24 kg ve 56,48 $\mathrm{kg}$ bulunmuştur. Güreşçilerin gruplara göre yaş, vücut ağırlıkları ve boy uzunlukları arasında anlamlı farklılık bulunmuştur

Turkish Studies - Education, $\mathrm{X}(\mathrm{X})$ 
$(\mathrm{p}<0,001)$. Yaş gruplarına göre sıçrama, uzun atlama, el kavrama kuvvetleri, sağlık topu atma, 20 metre mekik koşusu, 30 metre sürat koşusu, 30 saniyede çekilen mekik sayısı ve otur uzan esneklik test değerleri ve anaerobik güç değerlerinde anlamlı farklılık bulunmuştur $(\mathrm{p}<0,001)$. Yaş gruplarına göre güreşçilerin ortalama 20 metre mekik koşusu, 30 metre sürat koşusu, 30 saniyede çekilen mekik sayısı ve otur uzan esneklik test değerleri arasında bulunan farklılık yaş farklılığına ve yaptıkları antrenmanların türüne de bağlı olabilir. Sonuç olarak sporcu eğitim merkezlerindeki güreşçilerde yaş kategorilerine göre bazı antropometrik ve motorik performans parametrelerinde istatistiksel olarak anlamlı farklılıklar bulunmuştur. Bu farklılıkların güreşçilerin takvim ve antrenman yaşları farklılığı yanında yaptıkları antrenman türünden de kaynaklandığı düşünülmektedir. Antrenmanlarda çekme çalışmaları yanında itme ve el kavrama çalışmalarına daha fazla ağırlık verilmesi önerilebilir.

Anahtar kelimeler: Güreşçi, Sporcu Eğitim Merkezi, Motor Performans

\section{Giriş}

Güreş spor dalında performansta kasların kuvveti, sinir ve kas koordinasyonu, reaksiyon zamanı, çeviklik, durağan ve hareket halinde mükemmel bir denge, yüksek seviyede anaerobik ve aerobik kapasite önemli etkenlerdir. En çok kullanılan enerji sistemleri ATP-CP ve Glikoliz (Laktik Asit) enerji yollarıdır. Güreş antrenmanlarında amaç bu özellikleri daha fazla geliştirmeye yönelik olabilir (Otağ ve ark.,2011; Bayraktar ve ark.,2012). Güreş hem vücudun üst hemde alt bölümleri kas gücü için aralıklı aktiviteleri barındıran bir spor branşı olma hüviyetindedir (Bali ve ark., 2018). Özellikle tüm vücudu dengede tutma ve hareketleri uygularken gerçekleştirilen hızlı pozisyon değişimlerinde dengede kalabilme çok gereklidir (Alpay ve Işık 2017; Atılgan 2013). Özellikle güreşçilerin birbirlerini çekme ve itmeleri gibi hareketler çokça yapılır (İri ve ark., 2018). Fiziksel özellikler ve motor performans parametreleri yaşa ve cinsiyete göre değişir (İmamoğlu ve Şener,2019). Güreş Türklerin tarih boyunca en popüler sporu olarak son zamanlara kadar gelmiş̧ir (Türkmen ve Canuzakov,2019; Türkmen ve vd.,2006).

Sporun birçok faydaları bulunmaktadır. Bunlar sosyal, kültürel gelişim yanında bedensel olarak görülebilir. Örneğin kültürel olarak spor Liderlik özelliğini geliştirir (Çetinkaya ve İmamoğlu,2018). Bedensel olarak motorik özellikler ön plana çıkar. Sporcunun başarısı kuvvet, hız, esneklik ve sıçrama tekniği performansının gelişmesine bağlıdır (İmamoğlu ve ark. 2018). Fiziksel uygunluğu; yaş, boy uzunluğu, vücut ağırlığ 1 , aerobik ve anaerobik güç, vücut bileşeni, esneklik, dinlenme halindeki kalp atım sayısı ve kan basıncı gibi birçok parametre etkiler (Koca ve ark.,2018; Bostanc1 ve ark.,2019). Hız erkekler için, ilk hız antrenmanı bölümü 7-9 yaș arasında, ikinci așaması ise 13 ila 16 yaş arasında gerçekleşir. En uygun beceri eğitimi aşaması ise erkekler için 9 yaşında, kızlar için 8 yaşındadır. Esneklik ise hem erkek hem de kız çocuklarında esneklik için en uygun eğitilebilirlik aşamas 6- 10 yaşları arasındadır (Güneş ve ark.,2019). İyi bir vücut duruşu veya postur gelişimi performans için temeldir (Yamak ve ark.,2018).

Güreş branşında kısa süreler içerisinde çok çabuk hareketler yapılması gerekir. Aerobik güç yanında anaerobik güç oldukça önemlidir. Yine minder güreşinde başarı yüksek oranda vücut kuvvetine bağlı ortaya çıkar. Kuvvet hem savunma yaparken hemde hücum ederken tekniğin yapılmasında önemlidir. Ayrıca yapılan tekniğe karşı koyabilmede ve ona karşılık oyun yapabilmede çok önem arz eder (Ağaoğlu ve ark.,2010). Güreş sporunda esneklik de başarı için başka bir temel etkendir. Esneklik özelliği güreşçiye geniş acılarda hareket edebilme durumu sağlayarak tekniklerin uygulanmasında olumlu katkı sağlar. Sürat ve reaksiyon sürati; güreşçinin başarısını etkileyen temel etkenlerden biri olarak gereklidir. Bir güreşçi müsabaka sırasında hücum etme, savunma yapma veya yapılan oyunlara karşılık kontratakları süratli bir şekilde yapmak zorundadır (Aslan ve ark.,2013; Cicioğlu ve ark.,2007; Ziyagil ve ark.,1996).

Türk güreşinde güreş eğitim merkezleri başarıya ulaşmakta önemli bir yer teşkil etmektedirler. Türk minder güreşinde güreş eğitim merkezleri önemli bir yer kaplamıştır. 
Güreşçilerin genel sağlık durumu, antropometrik - motorik ve teknomotorik özellikleri başarı için gereklidir. Özellikle öğrenme yeteneği ve buna hazır olma durumları, duygusal -bilişsel özellikler ile sosyal faktörlerde dikkate alınmalıdır ( İmamoğlu ve ark.,2018). Güreşçilerin başarılı olması onların bedensel- kondisyonel özellikleri yanında teknik kapasitelerinin iyi olmasına, motivasyonlarının yüksekliğine, müsabakalar sırasındaki durumlarına bağlı olabilir. Minder güreşinde güreşçilerin başarılı olmaları için gerekli olan özelliklerin tespiti ve geliştirilmesi derecesi testlerle ölçülür. Yüksek performans gösterebilmek için bedensel ve fizyolojik kapasitelerin tespit edilmesi ve gelişimlerinin izlenmesi gereklidir (Aslan ve ark.,2013).

Yazarlar genç güreşçilerin aerobik gücü, kas dayanıklılı̆g ve vücut kompozisyonunun antrenman ve müsabaka aktivitelerini etkilediğini bulmuşlardır. Bu durumda, bedensel özelliklerin kapsamlı ve orantılı bir şekilde geliştirilmesini kolaylaştıran genel antrenman sürecinin optimum şekilde oluşturulmasıyla özel önem kazanılır (Balushka, 2016 ). Bu çalışmanın amacı; sporcu eğitim merkezlerinde bulunan güreşçilerin bazı Antropometrik ve motorik performans parametrelerinin karşılaştırılmasıdır.

\section{Yöntem:}

Katılımcılar: Araştırmaya, Değişik illerde sporcu eğitim merkezlerinde düzenli antrenman yapan toplam 132 güreşçi katılmıştır. Katılımda gönüllülük ilkesine uyulmuştur. Güreşçilerin ölçümleri sporcu eğitim merkezlerine 2019 yılı Mayıs ayı içerisinde alınmıştır. Güreşçilerin takvim yaşlarına göre ölçümler değerlendirilmiştir. $\mathrm{Bu}$ çalışma 2020 yılından önce tamamlanmış olduğundan etik kurul raporu alınmasına gerek duyulmamıştır. Sadece yetkililerden izni alınarak ölçümler yapılmıştır.

Sporcu eğitim merkezindeki güreşçilerin antrenman programı: Sporcu eğitim merkezlerinde güreşçilere genel olarak benzer antrenman programı uygulanır. Temmuz-Ağustos ayları arasında; Temel teknik, beceriler ve kondisyon hareketleri vardır. Ekim- Kasım ayları arasında; Temel teknik, taktik, kuvvet, dayanıklık hareketleri yapılır. Aralık ve Ocak aylarında; Teknik, taktik, dayanıklık ve kuvvet hareketlerine devam edilir. Şubat, Mart ve Nisan aylarında; Teknik, taktik, müsabakaya yönelik maçlar yapılır. Haftada 5 gün antrenman yapılmıştır (Haftalık 550 dakika antrenman). Yüklenme Şiddeti \%50-90 arasında olmasına dikkat edilir. Antrenmanlarda her çalışmada $20 \mathrm{dk}$ Jimnastik ağırlıklı Isınma, $40 \mathrm{dk}$ temel teknik çalışması ve 10 dakika germe hareketleri yaptırılır. Bu genel programdan sapme gösterenler olabilir. Bu çalışmanın zayıf noktası her sporcu eğitim merkezinde güreşçilere aynı tip programın uygulandığının varsayılmasıdır.

\section{Ölçümler:}

Kavrama Kuvveti: El dinamometresi güreşçilerin el ölçülerine göre ayarlanmıştır. Güreşçiler dirseğini bükmeden kolu düz uzatmışılardır. Her iki el ile 2 denemeden sonra en iyi performans alınmıştır (Günay ve ark. 2006).

Squat Sıçrama: Güreşçilerin dizleri 90 derece bükük çömelme pozisyonunda ve eller belde iken yukarı doğru tam bir sıçrama gerçekleştirilmiştir (Açıkada 2008).

Dikey sıçrama/Aktif sıçrama: Vertical Jump meter ile ölçülmüştür. İki deneme yapılarak en iyi değer kaydedildi (Harman ve Garhammer 2008).

Anaerobik Güç: Anaerobik gücün belirlenmesinde Dikey sıçrama yüksekliği kullanılmıştır. Formül aşağıdaki şekildedir.

$P=\sqrt{ } 4.9 \times$ A $\breve{g}$
$\sqrt{ } 4.9=$
Standart zaman

$$
\mathrm{P}=\text { Anaerobik Güç (kgm/sn) D=Dikey sıçrama mesafesi (m) }
$$


Durarak Uzun Atlama: Kolların ileri hareketi ile birlikte mümkün olduğunca ileriye ve en uzak mesafeye doğru sıçrama yapılmıştır. İki denemeden en iyisi alınmıştır (Pekel 2007; Mackenzie 2005).

Sağlık Topu Atma: Sağlık topu 2 kg'dır. Sağlık topu her iki el ile kavranarak başın gerisine götürülmüştür. Gövdeyi hafif geriye büktükten sonra kollar hızla öne savrularak top baş üstünden en uzak noktada atılmaya çalışılmıştır. İki denemeden en iyisi kaydedilmiştir ( Pekel 2007).

30 sn. Mekik: Güreşçiler başla komutuyla 30 saniye süreyle en fazla tekrar yapılacak şekilde hareketi gerçekleşmiştir. Tekrar edilen en fazla sayı kayıt edilmiştir. (Pekel 2007, Mackenzie 2005).

30 m. Sürat Koşusu: Güreşçiler hazır olduğunda çıkış yapmış ve bitiş çizgisini mümkün olan en kısa sürede geçmeye çalışmıştır. İki deneme sonrası en iyi derecesi kaydedilmiştir (Mackenzie 2005, Açıkada 2008).

20 Metre Mekik Koşu Testi ve Maksimal $\mathbf{V O}_{2}$ : Güreşçiler 20 metrelik mesafeyi gidiş dönüş olarak koşmuşlardır. Testin uygulanışı: Yavaş bir koşu hızında $(8 \mathrm{~km} / \mathrm{s})$ başlar ve güreşçi duyduğu birinci sinyal sesinde koşmaya başlar. İkinci sinyal sesine kadar çizgiye ulaşmalıdır. İkinci sinyal sesini duyduğunda ise tekrar başlangıç çizgisine geri döner ve bu koşu hızı her dakikada 0,5 $\mathrm{km} / \mathrm{s}$ artan sinyallerle devam eder. Güreşçiler sinyali duyduğunda ikici sinyalde pistin diğer ucunda olacak şekilde temposunu ayarlarlar. Hız giderek artar. Güreşçi bir sinyal sesini kaçırıp ikincisine yetişirse teste devam eder. Eğer güreşçi iki sinyali üst üste kaçırırsa test bitmiş olur. Maksimal $\mathrm{VO}_{2}$ değeri $\mathrm{ml} / \mathrm{kg} / \mathrm{dk}$ cinsinden, mekik koşu test sonucuna bağlı dolaylı olarak ve değerlendirme tablosundan hesaplanır (Tamer 2000).

İstatistiksek işlemler: Verilerin analizinde SPSS 23,0 paket programı kullanılmıştır. İstatistiksel işlemlerde tek yönlü varyans analizi ve farklılığın tespiti içinde Tukey testleri kullanılmıştır. Anlamlılık $\mathrm{p}<0,05$ düzeyinde değerlendirilmiştir.

\section{Bulgular}

Güreşçilerin antropometrik ve motorik özelliklere ilişkin ortalama değerleri ve karşılaştırma sonuçları sırasıyla tablolarda verilmektedir.

Tablo 1: Sporcu eğitim merkezleri güreşçilerinin yaş gruplarına göre antropometrik özellikleri değişimi

\begin{tabular}{|c|c|c|c|c|c|}
\hline Değişkenler & Yaş grubu & $\mathrm{n}$ & Ortalama & St sapma & F/Tukey \\
\hline \multirow[t]{4}{*}{ Yaş (Yıl) } & $12(1)$ & 33 & 11,94 & 1,22 & \multirow{4}{*}{$\begin{array}{l}33,48^{* *} \\
1<2,3,4 \\
2<3,4 \\
3<4\end{array}$} \\
\hline & $13(2)$ & 33 & 12,91 & 1,23 & \\
\hline & $14(3)$ & 33 & 13,94 & 1,32 & \\
\hline & $15(4)$ & 33 & 14,88 & 1,27 & \\
\hline \multirow{4}{*}{$\begin{array}{l}\text { Boy uzunluğu } \\
(\mathrm{cm})\end{array}$} & $12(1)$ & 33 & 147,24 & 10,20 & \multirow{4}{*}{$\begin{array}{l}8,87 * * \\
1<2,3,4 \\
2<3,4\end{array}$} \\
\hline & $13(2)$ & 33 & 153,00 & 11,23 & \\
\hline & $14(3)$ & 33 & 157,24 & 10,73 & \\
\hline & $15(4)$ & 33 & 159,45 & 9,23 & \\
\hline \multirow{4}{*}{$\begin{array}{l}\text { Vücut ağırlığ } \\
\text { (kg) }\end{array}$} & $12(1)$ & 33 & 41,24 & 12,23 & \multirow{4}{*}{$\begin{array}{l}7,61 * * \\
1<2,3,4 \\
2<4\end{array}$} \\
\hline & $13(2)$ & 33 & 47,82 & 13,26 & \\
\hline & $14(3)$ & 33 & 53,14 & 13,71 & \\
\hline & $15(4)$ & 33 & 56,48 & 13,46 & \\
\hline
\end{tabular}

$* * \mathrm{p}<0.001$ 
Tablo 2: Sporcu eğitim merkezleri güreşçilerinin yaş gruplarına göre sıçrama, atlama ve anaerobik güç değerleri karşılaştırılması

\begin{tabular}{|c|c|c|c|c|c|}
\hline Değişkenler & Yaş grubu & $\mathrm{n}$ & Ortalama & St sapma & F/Tukey \\
\hline \multirow{4}{*}{$\begin{array}{l}\text { Squat siçrama } \\
(\mathrm{cm})\end{array}$} & $12(1)$ & 33 & 22,97 & 8,54 & \multirow{4}{*}{$\begin{array}{l}22,08 * * \\
1<2,3,4 \\
2<4\end{array}$} \\
\hline & $13(2)$ & 33 & 29,72 & 5,38 & \\
\hline & $14(3)$ & 33 & 32,18 & 4,82 & \\
\hline & $15(4)$ & 33 & 34,03 & 3,86 & \\
\hline \multirow{4}{*}{$\begin{array}{l}\text { Aktif sıçrama } \\
(\mathrm{cm})\end{array}$} & $12(1)$ & 33 & 21,06 & 6,32 & \multirow{4}{*}{$\begin{array}{l}13,16 * * \\
1<2,3,4 \\
2<4\end{array}$} \\
\hline & $13(2)$ & 33 & 28,97 & 5,25 & \\
\hline & $14(3)$ & 33 & 29,76 & 5,51 & \\
\hline & $15(4)$ & 33 & 32,21 & 4,39 & \\
\hline \multirow{4}{*}{$\begin{array}{l}\text { Uzun } \\
\text { Atlama }(\mathrm{cm})\end{array}$} & $12(1)$ & 33 & 160,30 & 20,96 & \multirow{4}{*}{$\begin{array}{l}14,66 * * \\
1<2,3,4 \\
2<4\end{array}$} \\
\hline & $13(2)$ & 33 & 176,58 & 21,97 & \\
\hline & $14(3)$ & 33 & 185,70 & 18,35 & \\
\hline & $15(4)$ & 33 & 190,88 & 19,02 & \\
\hline \multirow{4}{*}{$\begin{array}{l}\text { Anaerobik güç } \\
(\mathrm{kg} \cdot \mathrm{m} / \mathrm{sn})\end{array}$} & $12(1)$ & 33 & 41,96 & 20,70 & \multirow{4}{*}{$\begin{array}{l}10,46 * * \\
1<2,3,4 \\
2<4\end{array}$} \\
\hline & $13(2)$ & 33 & 56,97 & 19,91 & \\
\hline & $14(3)$ & 33 & 64,42 & 19,77 & \\
\hline & $15(4)$ & 33 & 70,72 & 20,18 & \\
\hline
\end{tabular}

$* * \mathrm{p}<0.001$

Tablo 3: Sporcu eğitim merkezleri güreşçilerinin yaş gruplarına göre el kavrama ve sağlık topu atma değerleri karşılaştırılması

\begin{tabular}{|c|c|c|c|c|c|}
\hline Değişkenler & Yaş grubu & $\mathrm{n}$ & Ortalama & St sapma & F/Tukey \\
\hline \multirow{4}{*}{$\begin{array}{l}\text { Sağ el kavrama } \\
\text { kuvveti(kg) }\end{array}$} & $12(1)$ & 33 & 21,51 & 8,09 & \multirow{4}{*}{$\begin{array}{l}15,82^{* *} \\
1<2,3,4 \\
2<3,4\end{array}$} \\
\hline & $13(2)$ & 33 & 28,25 & 9,35 & \\
\hline & $14(3)$ & 33 & 34,08 & 9,47 & \\
\hline & $15(4)$ & 33 & 34,80 & 8,71 & \\
\hline \multirow{4}{*}{$\begin{array}{l}\text { Sol el kavrama } \\
\text { kuvveti(kg) }\end{array}$} & $12(1)$ & 33 & 21,56 & 7,97 & \multirow{4}{*}{$\begin{array}{l}16,09 * * \\
1<2,3,4 \\
2<3,4\end{array}$} \\
\hline & $13(2)$ & 33 & 28,32 & 9,19 & \\
\hline & $14(3)$ & 33 & 34,78 & 9,64 & \\
\hline & $15(4)$ & 33 & 34,82 & 9,35 & \\
\hline \multirow{4}{*}{$\begin{array}{l}\text { Sağlik topu atma } \\
(\mathrm{cm})\end{array}$} & $12(1)$ & 33 & 503,94 & 143,96 & \multirow{4}{*}{$\begin{array}{l}9,30 * * \\
1,2<3,4\end{array}$} \\
\hline & $13(2)$ & 33 & 574,55 & 158,92 & \\
\hline & $14(3)$ & 33 & 651,97 & 141,38 & \\
\hline & 15 (4) & 33 & 673,18 & 137,28 & \\
\hline
\end{tabular}

$* * \mathrm{p}<0.001$ 
Tablo 4: Sporcu eğitim merkezleri güreşçilerinin yaş gruplarına göre sürat ve esneklik özellikleri değişimi

\begin{tabular}{|c|c|c|c|c|}
\hline Değișkenler & Yaş Grubu & Ortalama & St sapma & F/Tukey \\
\hline \multirow{4}{*}{$\begin{array}{l}20 \text { metre mekik koşusu } \\
(\mathrm{ml} / \mathrm{kg} / \mathrm{dk})\end{array}$} & $12(1)$ & 63,09 & 14,28 & \multirow{4}{*}{$\begin{array}{l}10,27 * * \\
1<3,4 \\
2<4\end{array}$} \\
\hline & $13(2)$ & 68,79 & 14,57 & \\
\hline & $14(3)$ & 74,24 & 13,17 & \\
\hline & $15(4)$ & 81,88 & 15,30 & \\
\hline \multirow{4}{*}{$\begin{array}{l}30 \text { metre sürat koşusu } \\
(\mathrm{sn})\end{array}$} & $12(1)$ & 5,30 & 0,37 & \multirow{4}{*}{$\begin{array}{l}38,31 * * \\
1,2>3,4 \\
4<3\end{array}$} \\
\hline & $13(2)$ & 5,15 & 0,43 & \\
\hline & $14(3)$ & 4,96 & 0,43 & \\
\hline & $15(4)$ & 4,74 & 0,36 & \\
\hline \multirow{4}{*}{30 saniye mekik (Sayı) } & $12(1)$ & 21,58 & 4,33 & \multirow{4}{*}{$\begin{array}{l}24,02^{* *} \\
1<2,3,4 \\
2<3,4 \\
3<4\end{array}$} \\
\hline & $13(2)$ & 25,52 & 4,59 & \\
\hline & $14(3)$ & 26,88 & 4,13 & \\
\hline & $15(4)$ & 31,79 & 2,67 & \\
\hline \multirow{4}{*}{$\begin{array}{l}\text { Otur uzan esneklik } \\
(\mathrm{cm})\end{array}$} & $12(1)$ & 33,94 & 4,83 & \multirow{4}{*}{$\begin{array}{l}24,90 * * \\
1>2,3,4 \\
4>2,3\end{array}$} \\
\hline & $13(2)$ & 25,03 & 4,92 & \\
\hline & $14(3)$ & 24,30 & 5,61 & \\
\hline & $15(4)$ & 27,86 & 4,77 & \\
\hline
\end{tabular}

$* * \mathrm{p}<0.001$

\section{Tartıșma ve Sonuc}

Sporcu eğitim merkezleri güreşçilerinin vücut profilleri incelendiğinde Vücut ağırlıkları (VA) 12 yaşındakilerde ortalama $41,38 \mathrm{~kg}$ ve 15 yaşındakilerde $57,65 \mathrm{~kg}$ bulunmuştur. Boy uzunlukları ise 12 yaşındakilerde 146,34 cm ve 15 yaşındakilerde $162,35 \mathrm{~cm}$ olarak belirlenmiştir ( Tekelioğlu ve ark,2010). Bu çalışmada sporcu eğitim merkezi güreşçilerinin yaş ortalaması 12 yaşında olanlar için 11,94 yıl ve 15 yaş kategorisinde olanlar için 14,88 yıl şeklindedir. Boy uzunlukları ise 12 yaşında olanlar $147,24 \mathrm{~cm}$ ve 15 yaşında olanlar için $159,45 \mathrm{~cm}$ bulunmuştur. VA ise 12 yaş için $41,24 \mathrm{~kg}$ ve 15 yaş için $56,48 \mathrm{~kg}$ bulunmuştur. Güreşçilerin yaş gruplarına göre yaş, vücut ağırlıkları ve boy uzunlukları arasında anlamlı farklılık bulunmuştur $(\mathrm{p}<0.001)$.

Sporcu eğitim merkezleri güreşçilerinin vücut profilleri incelendiğinde squat sıçrama 12 yaşındakilerde ortalama $24,18 \mathrm{~cm}$ ve 15 yaşındakilerde $29,21 \mathrm{~cm}$ bulunmuştur (Tekelioğlu ve ark,2010). Squat sıçrama değeri 14 yaş grubu güreşçilerde 27,55 cm (Bayraktar ve ark.,2012a) ve 15 yaş güreşçilerde 29,26 cm (Bayraktar ve ark.,(2012b) bulunmuştur. Bu çalışmada Güreşçilerin yaşlara göre ortalama squat sıçrama değerleri 12 yaş için $22,97 \mathrm{~cm}$ ve 15 yaş için $34,03 \mathrm{~cm}$ bulunmuştur. Güreşçilerin yaşlara göre ortalama squat sıçrama değerleri istatistiksel olarak anlamlı bulunmuştur $(\mathrm{p}<0,001)$.

Güreş eğitim merkezleri güreşçilerinin vücut profilleri incelendiğinde aktif sıçrama 12 yaşındakilerde ortalama $25,87 \mathrm{~cm}$ ve 15 yaşındakilerde $31,27 \mathrm{~cm}$ bulunmuştur ( Tekelioğlu ve ark,2010). Bu çalışmada güreşçilerin yaşlara göre ortalama aktif sıçrama değerleri 12 yaş için 21,06 $\mathrm{cm}$ ve 15 yaş grubu için $32,21 \mathrm{~cm}$ bulunmuştur. Güreşçilerin yaşlara göre aktif sıçrama değerleri istatistiksel olarak anlamlı bulunmuştur $(\mathrm{p}<0,001)$.

Sporcu eğitim merkezleri güreşçilerinin vücut profilleri incelendiğinde uzun atlama 12 yaşındakilerde ortalama $167,51 \mathrm{~cm}$ ve 15 yaşındakilerde 198,90 $\mathrm{cm}$ bulunmuştur ( Tekelioğlu ve ark,2010). Bağçı (2016) 12-14 Yaş Arası Güreşçilerde yaptığı bir çalışmada uzun atlama değerini ilk ölçümde 194,10 cm ve 8 haftalık çalışmalardan sonraki ölçümde 198,00 cm bulmuştur. Aslan ve ark., (2013) 13-15 yaş grubu güreşçilerde durarak uzun atlama değerini bir y1llık sürede ilk ölçümde $184,2 \mathrm{~cm}$ ve son ölçümde 182,7 cm bulmuşlardır. Durarak uzun atlama değeri 14 yaş grubu güreşçilerde 181,94 cm (Bayraktar ve ark.,2012a) ve 15 yaş güreşçilerde 197,95 cm (Bayraktar ve 
ark.,(2012b) bulunmuştur. Bu çalışmada uzun atlama 12 yaş grubu için 160,30 cm iken 15 yaş grubu için 190,88 cm bulunmuştur. Güreşçilerin yaşlara göre ortalama uzun atlama değerleri istatistiksel olarak anlamlı bulunmuştur $(\mathrm{p}<0,001)$.

Sporcu eğitim merkezleri güreşçilerinin vücut profilleri incelendiğinde anaerobik güç 12 yaşındakilerde ortalama $46,54 \mathrm{kgm} / \mathrm{sn}$ ve 15 yaş grubundakilerde $71,39 \mathrm{kgm} / \mathrm{sn}$ bulunmuştur ( Tekelioğlu ve ark,2010). Bir çalışmada Bayraktar ve ark.,(2012b) bir çalışmada 15 yaş güreşçilerde anaerobik güç değerini 73,63 kgm/sn bulmuşlardır. Bu çalışmada Anaerobik güç değeri ise 12 yaş grubu için 41,96 kgm/sn iken 15 yaş grubu için $70,72 \mathrm{kgm} / \mathrm{sn}$ bulunmuştur. Yaş ile anaerobik güç değerlerindeki değişim anlamlı bulunmuştur $(\mathrm{p}<0.001)$.

$\mathrm{Bu}$ çalışmada güreşçilerin yaş gruplarına göre sıçrama ve uzun atlama mesafeleri ile anaerobik güç değerleri farklı olması yaşa bağlı değişim yanında yaptıkları antrenman yılına ve şekline de bağlı olabilir.

Sporcu eğitim merkezleri güreş̧̧ilerinin el kavrama kuvvetleri 12 yaş grubundakilerde ortalama sağ el 23,33 kg ve sol el 22,60 kg, 15 yaşındakilerde sağ el 37,04 kg ve sol el 36,24 kg bulunmuştur ( Tekelioğlu ve ark,2010). Bağçı (2016) 12-14 yaş Arası Güreşçilerde yaptığı bir çalışmada el kavrama kuvveti değerlerini ilk ölçümde sağ elde $35,15 \mathrm{~kg}$ ve sol elde $35,40 \mathrm{~kg}$ iken 8 haftalık çalışmalardan sonraki ölçümde sağ elde $38,90 \mathrm{~kg}$ ve sol elde $38,45 \mathrm{~kg}$ olarak bulmuştur. Aslan ve ark., (2013) 13-15 yaş grubu güreşçilerde el kavrama kuvvetini bir y1llık sürede ilk ölçümde $26,1 \mathrm{~kg}$ ve son ölçümde 34,8 kg bulmuşlardır. Bayraktar ve ark.,(2012b) bir çalışmada 14 yaş güreşçilerde el kavrama kuvvetini sağ ve sol elde 32,65-32,47 kg bulmuşlardır. Başka bir çalışmada Bayraktar ve ark.,(2012b) 15 yaş güreşçilerde el kavrama kuvvetini sağ ve sol elde 37,98-37,58 kg bulmuşlardır. Bu çalışmada güreşçilerin el kavrama kuvvetleri 12 yaş grubu için sağ el $21,51 \mathrm{~kg}$ ve sol el 21,56 kg iken 15 yaş grubu için sağ el 34,80 kg ve sol el 34,82 kg bulunmuştur. Yaş gruplarına göre el kavrama kuvvetleri arasında anlamlı farklılık bulunmuştur ( $<<0,001)$. Bizim çalışmamız Tekelioğlu ve ark., (2010) ile Aslan ve ark., (2013) çalışmaları ile benzerdir. Yaş arttıkça el kavrama kuvveti artışı beklenen bir durumdur. İlave olarak yapılan antrenmanlara bağlı olarak el kavrama kuvveti artabilir.

Sporcu eğitim merkezleri güreşçilerinin sağlık topu atma değerleri 12 yaş grubundakilerde sağlık topunu atma 465 metre iken 15 yaş grubundakilerde 703 metre bulunmuştur ( Tekelioğlu ve ark,2010). Aslan ve ark., (2013) 13-15 yaş grubu güreşçilerde sağl1k topunu atma mesafesini bir y1llık sürede ilk ölçümde $554 \mathrm{~cm}$ ve son ölçümde $612 \mathrm{~cm}$ bulmuşlardır. Bayraktar ve ark.,(2012b) bir çalışmada 15 yaş güreşçilerde sağlık topunu atma mesafesi $729 \mathrm{~cm}$ olarak bulmuşlardır. Bu çalı̧̧mada Güreşçilerin sağlık topunu atma 12 yaş grubunda $503,94 \mathrm{~cm}$ ve 15 yaş grubunda 673,18 cm'ye çıkmıştır. Çalışmamızda sağlık topu atma değerleri arasında yaş gruplarına göre anlamlı şekilde farklı bulunmuştur $(\mathrm{p}<0,001)$. Sağlık topu atmada $14-15$ yaş grubundaki değişimin anlamsız olması güreşte antrenmanların çoğunlukla çekme türünde yapılmasına bağlanabilir. Çekme çalışmaları yanında itme ve el kavrama çalışmalarına daha fazla ağırlık verilmesi önerilebilir.

Sporcu eğitim merkezleri güreşçilerinin vücut profilleri incelendiğinde 20 metre mekik koşusu değerleri 12 yaş grubundakilerde ortalama $69,06 \mathrm{~mL} / \mathrm{kg} / \mathrm{dk}$ ve 15 yaşındakilerde 88,06 $\mathrm{mL} / \mathrm{kg} / \mathrm{dk}$ bulunmuştur ( Tekelioğlu ve ark,2010). Bu çalışmada Güreşçilerin 20 metre mekik koşusu değerleri 12 yaş grubunda ortalama $63,09 \mathrm{~mL} / \mathrm{kg} / \mathrm{dk}$ iken 15 yaş grubunda $81,88 \mathrm{~mL} / \mathrm{kg} / \mathrm{dk}$ bulunmuştur. Yaş gruplarına göre güreşçilerin ortalama 20 metre mekik koşusu değerleri arasında değişim istatistiksel olarak anlamlı bulunmuştur $(\mathrm{p}<0,001)$.

Sporcu eğitim merkezleri güreşçilerinin 30 metre koşusu değerleri 12 yaş grubu ortalama 5,20 sn ve 15 yaşındakilerde 4,73 sn bulunmuştur ( Tekelioğlu ve ark,2010). Aslan ve ark., (2013) 13-15 yaş grubu güreşçilerde 30 metre sprint değerini bir yıllık sürede ilk ölçümde 4,98 sn ve son ölçümde 4,97 sn bulmuşlardır. 30 metre sürat koşusu değeri 14 yaş grubu güreşçilerde 4,94 sn (Bayraktar ve ark.,2012a) ve 15 yaş güreşçilerde 4,76 cm (Bayraktar ve ark.,(2012b) bulunmuştur. 
Bu çalışmada 30 metre sürat koşusu değerleri 12 yaş grubunda ortalama 5,30 sn iken 15 yaş grubunda 4,74 saniyeye düşmüş̧ür. Yaş gruplarına göre güreşçilerin ortalama 30 metre sürat koşusu değerleri arasında değişim istatistiksel olarak anlamlı bulunmuştur $(\mathrm{p}<0,001)$.

Sporcu eğitim merkezleri güreşçilerinin 30 sn mekik sayısı 12 yaşındakilerde ortalama 27,81 adet ve 15 yaşındakilerde 32,25 adet bulunmuştur ( Tekelioğlu ve ark,2010). Aslan ve ark., (2013) 13-15 yaş grubu güreşçilerde 30 sn mekik sayısını bir yıllık sürede ilk ölçümde 23,9 adet ve son ölçümde 27,4 adet bulmuşlardır. Bayraktar ve ark.,(2012b) bir çalışmada güreşçilerde 30 saniyede çekilen mekiği 31,98 adet olarak bulmuşlardır. Bu çalışmada Güreşçilerin 30 saniyedeki mekik sayıs1 12 yaş grubunda ortalama 21,57 adet iken 15 yaş grubunda 31,79 adet bulunmuştur. Yaş gruplarına göre güreşçilerin 30 saniyede çekilen mekik sayı değerleri arasında değişim istatistiksel olarak anlamlı bulunmuştur $(\mathrm{p}<0,001)$.

Gül ve ark., (2012) yaptıkları bir çalışmada otur uzan esneklik testinde de yaş gruplarına göre anlamlı bir fark olduğunu belirtmişlerdir. İmamoğlu ve ark.(2018) yaptıkları bir çalışmada otur uzan test değeri en az $41 \mathrm{~kg}$ güreşçilerinde $17,90 \mathrm{~cm}$ bulunurken en yüksek $37 \mathrm{~kg}$ güreşçilerinde 22,06 cm bulmuştur. Özal (1999-2000 Öğretim Y1l1) esneklik ölçümlerini güreş eğitim merkezleri sinavinda kazananlarda 15,63 cm bulurken, kaybedenlerde 11,49 cm bulmuştur. Bağ c1 (2016) 12-14 yaş arası güreşçilerde esneklik performansı ortalamasını ilk ölçümde 20,85 ve son ölçümde 24,35 $\mathrm{cm}$ olarak bulmuştur. Bu çalışmada otur uzan esneklik testi değerleri 12 yaş grubunda ortalama 33,94 $\mathrm{cm}$ iken 15 yaş grubunda 27,86 cm'ye düşmüştür. Yaş gruplarına göre güreşçilerin otur uzan esneklik test değerleri arasında değişim istatistiksel olarak anlamlı bulunmuştur $(p<0,001)$.

Yaş gruplarına göre güreşçilerin ortalama 20 metre mekik koşusu, 30 metre sürat koşusu, 30 saniyede çekilen mekik sayısı ve otur uzan esneklik test değerleri arasında bulunan farklılık yaş farklılığına ve dolaylı olarak yaşı çok olanların daha fazla antrenman yapmasına ve yaptıkları antrenmanların türüne de bağlı olduğu söylenebilir.

Sporcu eğitim merkezlerindeki güreşçilerde yaş kategorilerine göre bazı antropometrik ve motorik performans parametrelerinde istatistiksel olarak anlamlı farkl1liklar bulunmuştur. $\mathrm{Bu}$ farklılıkların güreşçilerin takvim ve antrenman yaşları farklılığı yanında yaptıkları antrenman türünden de kaynaklandığı düşünülmektedir. Antrenmanlarda çekme çalışmaları yanında itme ve el kavrama çalışmalarına daha fazla ağırlık verilmesi önerilebilir.

\section{Kaynakça}

Ağaoğlu S.A., Tasmektepligil M.Y., Atan T., Tutkun E., Hazar F. (2010). Effects of Two Months Training on Blood Lactate Levels in Adolescent Swimmers, Biol. Sport. 27:135-141

Alpay, C. B., Işık, Ö. (2017). Comparison of body components and balance levels among hearingimpaired wrestlers and healthy wrestlers. Acta Kinesiologica, 11(1): 79-84.

Atılgan, O. E. (2013). Effects of Trampoline Training on Jump, Leg Strenght, Static and Dynamic Balance of Boys. Science of Gymnastics Journal, 5(2): 15 - 25

Aydos, L., Pepe, H., Karakuş, H. (2004). Bazı Takım Ve Ferdi Sporlarda Rölatif Kuvvet Değerlerinin Araştırılması. Gazi Üniversitesi Kırşehir Eğitim Fakültesi, 5(2):305-315.

Aydos L.,Taş M., Akyüz M., Uzun A. (2009). Genç Elit Güreşçilerde Kuvvetle Bazı Antropometrik Paremetrelerin İlişkisinin İncelenmesi, Atabesbd, 11 (4) : 1-10

Bağcı, O. (2016). 12-14 Yaş Arası Güreşçilerde 8 Haftalık Kuvvet Antrenmanının Bazı Fiziksel Uygunluk Parametrelerine Etkisi. Selçuk Üniversitesi Sağllk Bilimleri Enstitüsü Yüksek Lisans Tezi 
Bali, A.S.; Singh, L.; Singh, G.; Singh, B.(2018). Norms and Grades Under Normal Distribution for Basic Movement Patterns of Freestyle Wrestling Player, European Journal of Physical Education and Sport Science, 4(1):100-108

Balushka LM. (2016). Perfection of physical fitness of lyceum with advanced military physical training pupils by means of sports wrestling. Pedagogics, psychology, medical-biological problems of physical training and sports, 5: 4-10

Bayraktar I., Deliceoğlu G.,Kahraman E.,Kamiloğlu D. (2012a). A Investigation of Some Motoric Attributes Which Are Effecting the Endurance and the Velocity of Young Athletes and Wrestlers, Uluslararası Hakemli Akademik Sağlık ve Tip Bilimleri Dergisi,2 (2):47-55.

Bayraktar I., Deliceoğlu G.,Yaman M.,Yaman Ç. (2012b). The Comparison of Some Physical and Physiological Parameters of Sprinters And Throwers With Same Age Wrestlers, Uluslararası Hakemli Akademik Sağllk ve Tıp Bilimleri Dergisi, 3(2):36-45.

Bostanc1 Ö., Kabadayı M., Mayda M.H., Yılmaz A.K.,Yı1maz Ç. (2019). The differential impact of several types of sports on pulmonary functions and respiratory muscle strength in boys aged 8-12, Isokinetics and Exercise Science, 27: 307-312.

Cicioğlu Hİ, Kürkçü R, Eroğlu H, Yüksek S. (2007). 15-17 yaş grubu güreşçilerin fiziksel ve fizyolojik özelliklerinin sezonsal değişimi. Spormetre Beden Eğitimi ve Spor Bilimleri Dergisi 5: 151-156.

Çetinkaya G., İmamoğlu G. (2018). Research on Leadership Tendency of Students Taking Sports Education According Difference Variations, The Journal of International Social Research, 11(59):719-725.

Erikoğlu, Ö., Güzel, N.A., Pense, M., Örer, G.E. (2015). Comparison of Physical Fitness Parameters with EUROFIT Test Battery of Male Adolescent Soccer Players and Sedentary Counterparts, International Journal of Science Culture and Sport (IntJSCS), 3(3): 43-52.

Gül, M., İmamoğlu, O., Özdal, M., Doğan, A. (2012) Güreş Eğitim Merkezi Güreşçilerinin Fiziksel ve Fizyolojik Özelliklerinin İncelemesi. II. Uluslararası Geleneksel ve Olimpik Güreşler Sетроzуити, s. 21.

Günay M., Tamer K., Cicioğlu İ.(2006). Spor Fizyolojisi ve Performans Ölçümü, Baran Ofset.

Güneş S., Koca F., İmamoğlu O. (2019).The Effect of 8 Weekly Alpient Discipline Basic Ski Training on Balance, Flexibility, Quickness and Durability in Children 8-10 Age Groups, Turkish Studies, 14(1): 381-393, http://dx.doi.org/10.7827/TurkishStudies.14866.

Harman, E.; Garhammer, J. (2008). Administation, scoring, and interpretation of selected tests. In: Beachle TR, Earle RW, Eds. Essentials of Strength Training and Conditioning, 3rd Edition, Champaign, IL. Human Kinetics, s. 249-292.

İmamoğlu O.,Yamak B.,Çebi M.İslamoğlu İ. (2018). Antropometric and Motoric Characteristics of Certain Selected Primary School Student Wrestlers, The Journal of International Social Research, 11(59):1469-1474.

İmamoğlu, O., Çebi M.,Yıldız M. (2018).The Research Of Consecutive Sprint, Jump and Leg Strength Relationships in U15 Football Players, The Journal of International Social Research, 11(58): 913-918.

İmamoğlu M.,Şener O.A. (2019). Comparison of Children's Motor Performances by Age and Gender, Universal Journal of Educational Research,7(1): 10-15. 
İri, R., Engin, H., Aktuğ, Z.B. (2018). 12-15 Yaş Arası Güreşçilerde 8 Haftalık Denge Antrenmanının Denge Çeviklik ve Sürat Performansı Üzerine Etkisi. Gaziantep Üniversitesi Spor Bilimleri Dergisi, 3(1): 81-90.

Koca F., Güneş S., İmamoğlu O. (2019). Investigation of The Effect of 8 Weekly Alp Discipline Basic Skiing Training on Force and Advanced Spring in Children 8-10 Age Group, Turkish Studies Social Sciences, 14(3): 755-768. http://dx.doi.org/10.29228/TurkishStudies.22566

Mackenzie B.(2005). 101 Performance Evaluation Tests, Elektric Word plc.

Otağ A, Otağ İ. (2011). 12-14 yaş grubu erkek çocuklarda güreşin kardiyak etkileri: Bir ekokardiyografi çalışması. Cumhuriyet Tıp Dergisi, 33: 160-163.

Schmidt, W.D., Piencikowski, C.L., Vandervest, R.E. (2005). Effects Of A Competitive Wrestling Season On Body Composition, Strength And Power İn National Ccollegiate Athletic Association Division III College Wrestlers. Journal of Strength Cond. Research, 19(3):505508.

Şenel Ö, Taş, M., Harmancı H., Akyüz, M., Özkan, A., Zorba E. (2008). Güreşçilerde Vücut Kompozisyonu İle Anaerobik Performans, Bacak Kuvveti Ve Sirt Kuvveti Arasındaki İlişkinin Belirlenmesi.10.Uluslar Arası Spor Bilimleri Kongresi.

Tekelioğlu A., Hazır M.,Kabak B.,Ufuk P.(2010). "Vücut kompozisyonu", Sporcu Eğitim Merkezlerindeki Sporcuların Sağlık ve Performans Profilleri, (Editörler: Işık Bayraktar, Gökhan Deliceoğlu), Gençlik ve Spor Genel Müdürlüğü Sağlık İşleri Daire Başkanlığı, 86125.

Türkmen M.,Canuzakov K. (2019). Cultural Pedagogy of Traditional Wrestling of Turkish People, Turkish Studies, 14(6): 3525-3533. http://dx.doi.org/10.29228/TurkishStudies.30292

Türkmen M. İmamoğlu, O. Ziyagil M.A. (2006). Popularity of the Wrestling sport in Turkey and it's comparison with the selected sports, Researches About The Turks All Around The World,163: 77-94

Yamak B. İmamoğlu O., İslamoğlu İ., Çebi M., (2018). The Effects of Exercise on Body Posture, Turkish Studies Social Sciences, 13(18): 1377-1388, http://dx.doi.org/10.7827/TurkishStudies.13911

Ziyagil MA, Zorba E, Kutlu M, Tamer K, Torun K. (1996). Bir yıllık antrenmanın yıldızlar kategorisindeki Serbest Stil Türk Milli Takım güreşçilerinin vücut kompozisyonu ve fizyolojik özellikleri üzerine etkisi. G. Ü. Beden Eğitimi ve Spor Bilimleri Dergisi 1(4): 1219. 